\title{
ACTIVE AUTOMATIC CHASSIS ACTUATION FOR AN EXCAVATOR
}

\author{
Christoph Boes \\ Moog GmbH, Hanns-Klemm-Str. 28, 71034 Böblingen, Germany \\ Tel.: +49 7031 622-207; E-mail address: cboes@moog.com
}

\begin{abstract}
This paper shows an electrohydraulic control system to stabilize the chassis of a mobile machine driving across an off-road ground profile. The active hydraulic suspension system is based on new electronics, SW- and control architectures and the use of state of the art industrial components. The paper shows, that the static and dynamic performance of the system is dominated by the servo valve, which represents the central component of the system.
\end{abstract}

Keywords: Chassis Stabilization, Force Control, Active Suspension, Construction Machines, Forest Machines

\section{INTRODUCTION}

Mobile machines have been characterized by a limited increase of productivity over the last years compared to the industrial machinery. Know these markets are indicating several efforts to increase the productivity, the connectivity and the grade of automation in parallel with investigations to reduce the energy consumption of these systems. Typical phases of this development from manual operated machines to complete autonomous machines are

- Operator/driver assistance systems

- Teleoperated machines

- Autonomous machines

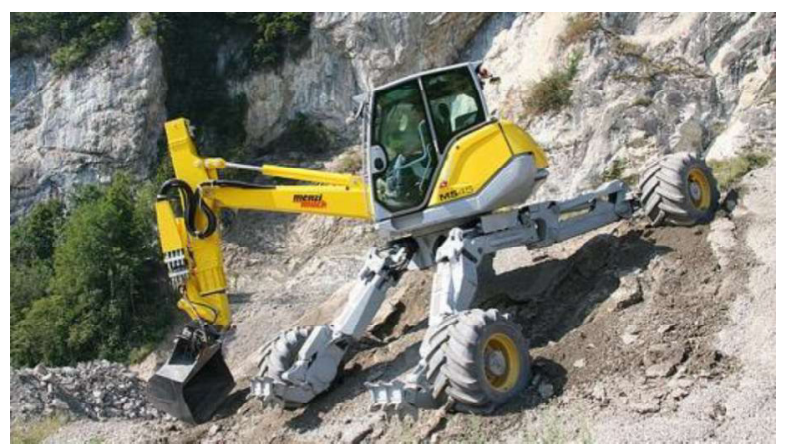

Figure 1: Spyder Excavator

Spider excavators as shown in Figure 1 are designed for operation in difficult terrain and areas, which are typically not easy to access. The number of skilled operators for these machines is limited and the biggest challenge is handling of the chassis actuators. This paper shows the development of a high-performance servo hydraulic actuation system for such mobile machines to allow an "easy drive" and/or teleoperated driving and later on an autonomous driving mode.

The stabilization of the vehicle platform during off road driving requires extreme high loop gains or performance in the force loops of the actuators. Typical mobile solutions based on proportional valves in combination with LS valves cannot fulfil these dynamic requirements. Industrial components, especially industrial direct drive servo valves fit much better to this application. In addition to the high bandwidth of the control valves typical industrial controller structures and elements like electronic pressure compensation, additional feedforward structures and gain scheduling are used to implement the dynamic stabilization of the platform.

\section{SYSTEM ARCHITECTURE CHASSIS}

The chassis is equipped with $12+2$ actuators as shown in Figure 2. Each leg consists of 3 actuators for

- Vertical movement

- Horizontal movement

- Steering

The chassis stabilization is done by the vertical actuators. The actual position of the other actuators is used for the kinematics and inverse kinematics calculation. 


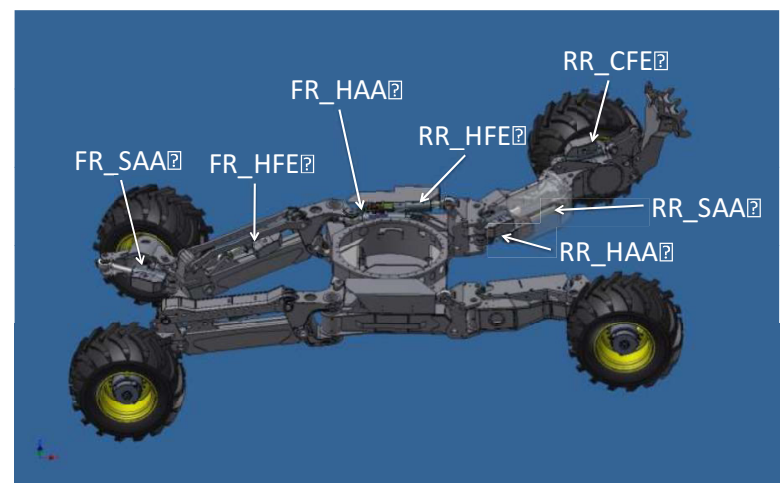

Figure 2: Chassis Actuators

The schematic sketch in Figure 3 shows the physical principal of used pendulum arm suspension. The kinematics could be linearized by a gear ratio of 3.98, which means $1 \mathrm{~mm}$ stroke of the hydraulic actuator effects a lift of the vehicle by $3.98 \mathrm{~mm}$.

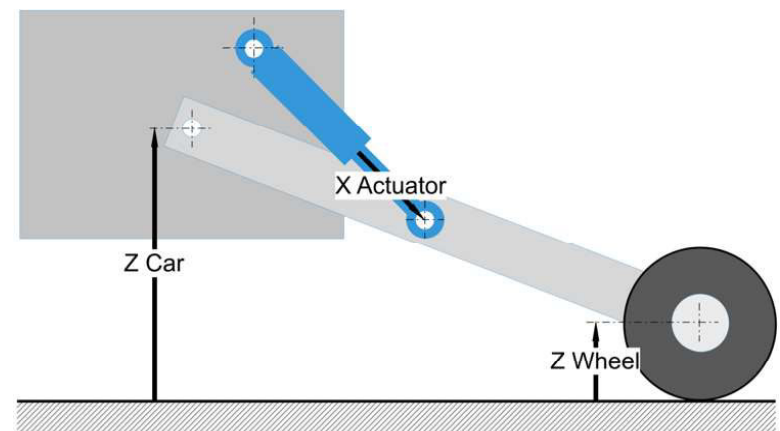

Figure 3: Pendulum Arm Suspension

\subsection{Electronic Topology}

The architecture of the chassis of the machine is based on a central controller unit, calculating demand values of the four-wheel ground contact forces and decentralized control loop structures integrated into the servo actuators as shown in Figure 4.

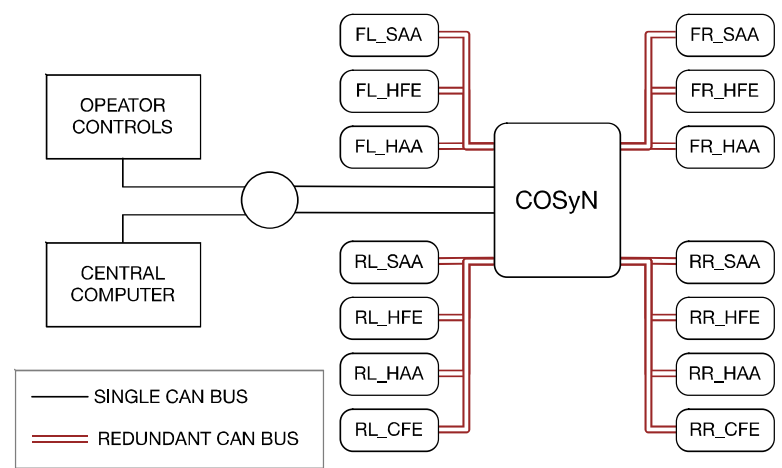

Figure 4: System Layout

The demand values for the high dynamic force loops are calculated by use of IMU / gyros and the online calculation of the inverse kinematics of the machine. The system is over determined and the solution is online solved numerically.

\subsection{Hydraulic Layout}

The hydraulic layout of a standard mobile machine in form of a central control manifold with standard proportional valves and LS valves and rubber hoses connecting the manifold and cylinder wouldn't allow the implementation of closed control loops with high dynamic performance. The controlling servo valve has been mounted directly on the hydraulic cylinder to minimize the impact of the hydraulic capacity between servo valve and hydraulic cylinder as shown in Figure 5.

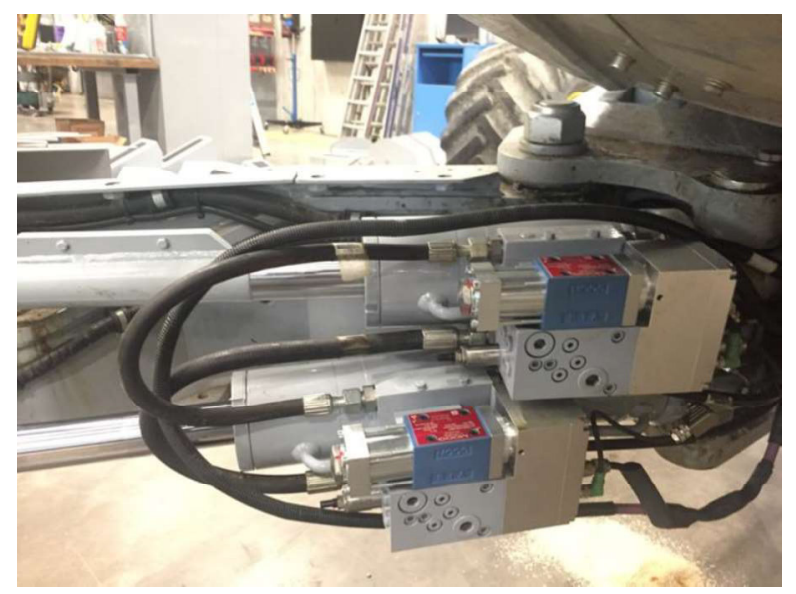

Figure 5: Hydraulic Actuator

The servo valve is integrated into a manifold, which contents all additional safety and measurement features.

The check valves CV1 and CV2 in Figure 6 are used to freeze the actuator in fail safe situations and protect the other hydraulic equipment against extreme pressures in the cylinder chambers, which could be effected by the kinematics of the machine while digging. The check valves and the supply pressure connection SO1 valve are operated by a small solenoid valve $\mathrm{SO} 2$, which can be deactivated by the internal SW and the external HW.

The actuator system contents all sensors and transducers to close the loops for

- Force control

- Position control

- Velocity control

in form 3 of pressure transducers, position transducer, IMU and temperature sensor. 


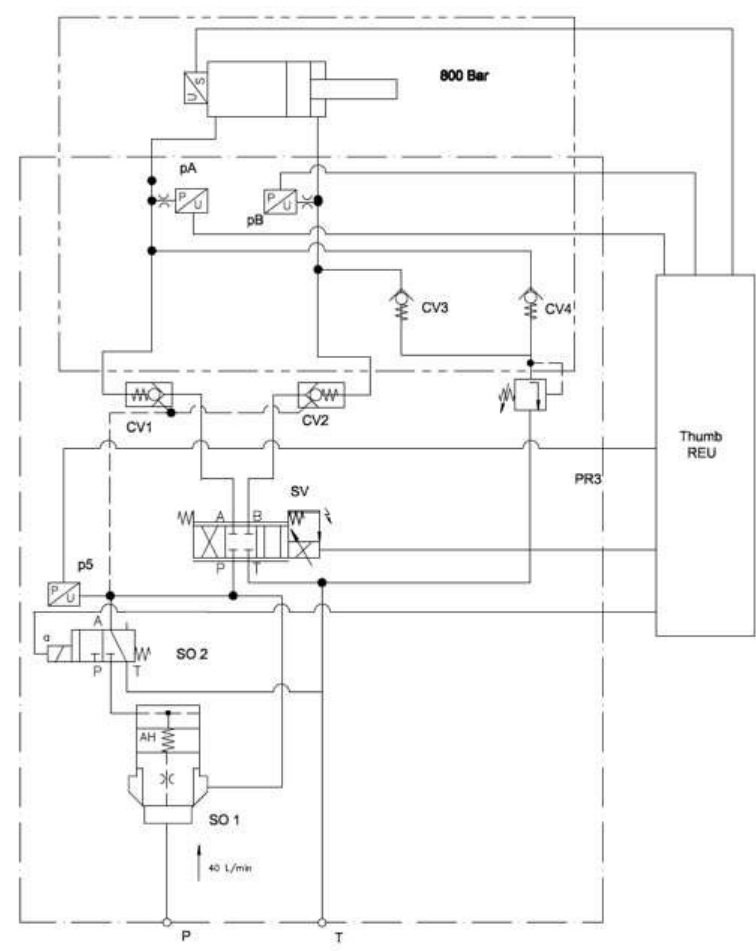

Figure 6: Hydraulic Circuit of the Actuator

Due to the dimensions of the circuit board of $55 \times 25 \mathrm{~mm}$ as shown Figure 7 the complete electronics could be integrated into the manifold of the actuator.

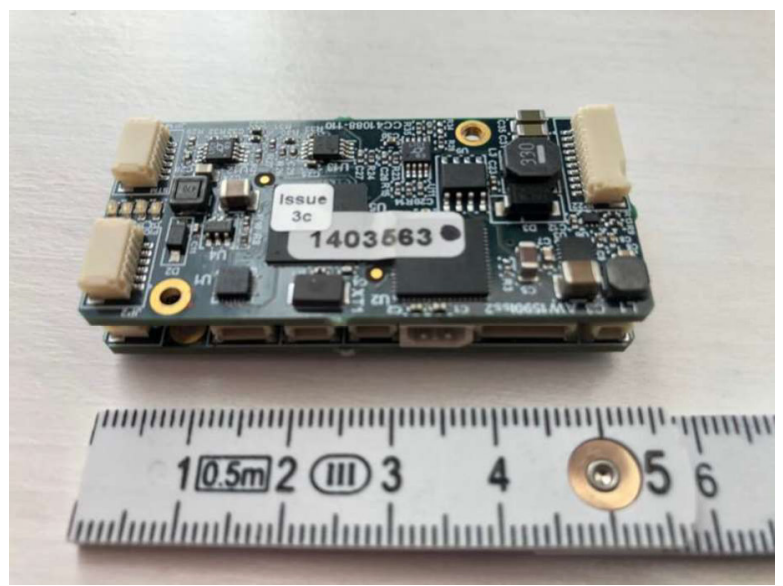

Figure 7: Actuator Electronics

\subsection{Controller Structure}

The central computer in Figure 4 and Figure 8 calculates the demand values for the internal control loops of the actuators. In the automatic chassis stabilization mode this means the demand value for the ground contact force of the wheels. The force-, position- and velocity-loop in Figure 9 are arranged as alternating loops depending of the commanded Control Mode. These loops command the two internal cascaded loops of the servo valve in form of spool loop control and current control.

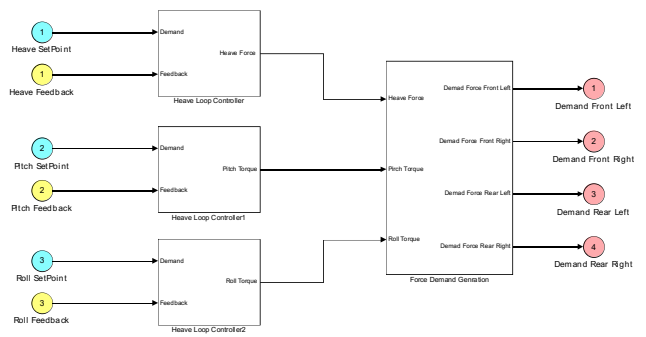

Figure 8: Chassis Controller Structure

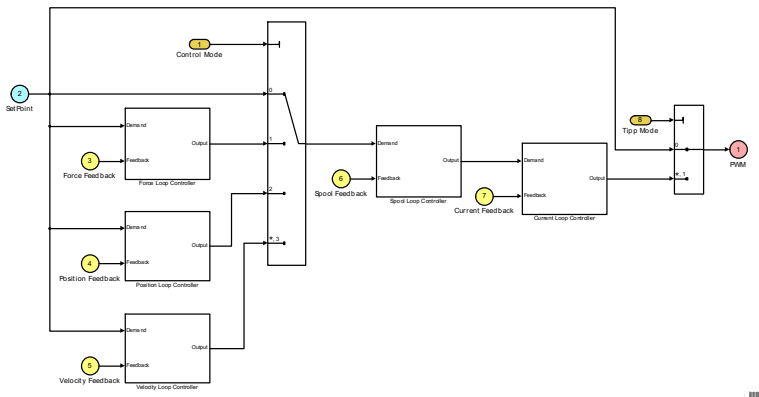

Figure 9: Actuator Controller Structure

The dynamic performance of the complete chassis stabilization system is characterized by the performance or bandwidth of each of the cascaded internal loops and will be discussed in the following.

\section{REFERENCE TRACK}

For the investigation of the performance of the chassis stabilization system a reference test track is needed. The discussed machine shows similarities or characteristics, which are close to forest machines. The Skogforsk Institute in Upsala/Sweden has designed a test track to test the characteristics of the suspension systems of harvester and forwarder machines [1].

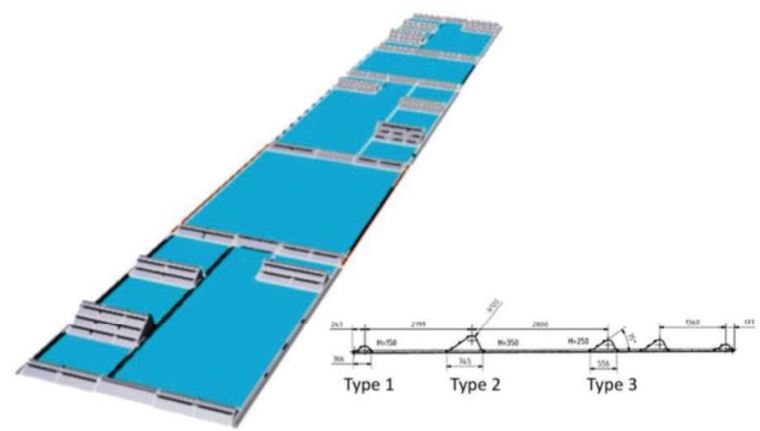

Figure 10: Skogforsk Reference Track

The test track shown in Figure 10 and Figure 11 implements a series of defined obstacles for the 
left and right wheel track. The obstacles are characterized by a rising slope of $35^{\circ}$ and a falling slope of $65^{\circ}$ with 3 different altitudes of $150 / 250 / 350 \mathrm{~mm}$. The typical driving speed for the forest machines in off road terrain and across this track amounts between $0.2 \mathrm{~m} / \mathrm{s}$ and $1 \mathrm{~m} / \mathrm{s}$.
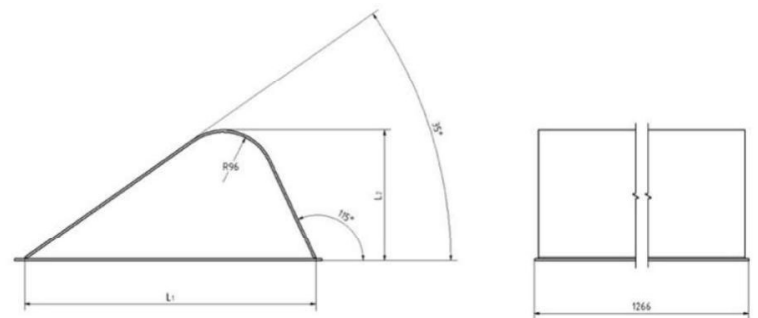

Figure 11: Obstacles of Skogforsk Reference Track

For the discussed excavator a driving speed of $1 \mathrm{~m} / \mathrm{s}=3.6 \mathrm{~km} / \mathrm{h}$ has been chosen as a reference.

The shown test track is easy to implement in a simulation model and has been used in the simulation models to design and investigate the chassis control system.

\section{SIMULATION MODEL}

In parallel to the tests on the real machine simulation models in form of complete car model and quarter model for more detailed and reproducible offline investigations have been developed. The tuned control parameters in the model and real machine deviate $10 \%$, so that the models seem to be precise enough.

\subsection{Quarter Car Model}

The ridged body model of the complete vehicle is characterized by a certain complexity and has several degrees of freedom. The force control loop could be identified as the dominant element determining the performance of the complete system.

The quarter car model has been established as powerful und effective tool for the study of the suspension system itself in vehicle dynamics. Figure 12 shows the reduced one-dimensional model of the vehicle as a two-mass-springdamper-system. The tire is shown as a combination of spring and damper, which effects only pushing forces. The wheel mass is actuated by the tire forces and the force of the hydraulic suspension actuator, considering a linear gear kinematics between vehicle body and the wheel as shown in Figure 3.

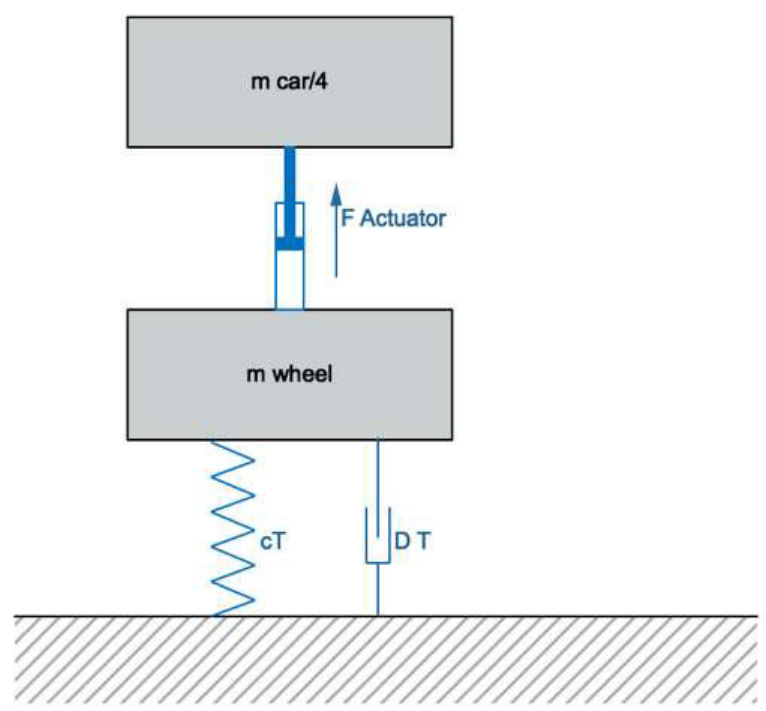

Figure 12: Quarter Car Model

Only a quarter of the mass of complete vehicle has been considered in the reduced onedimensional model of the vehicle.

The force loop controller is based on a linear core with several non linear compensation features. The step response of the force control loop in Figure 13 shows an aggressive, but robust tuning. The overshoot will be filtered out by low frequent vehicle dynamics while the focus more on an instant following the change in the demand value.

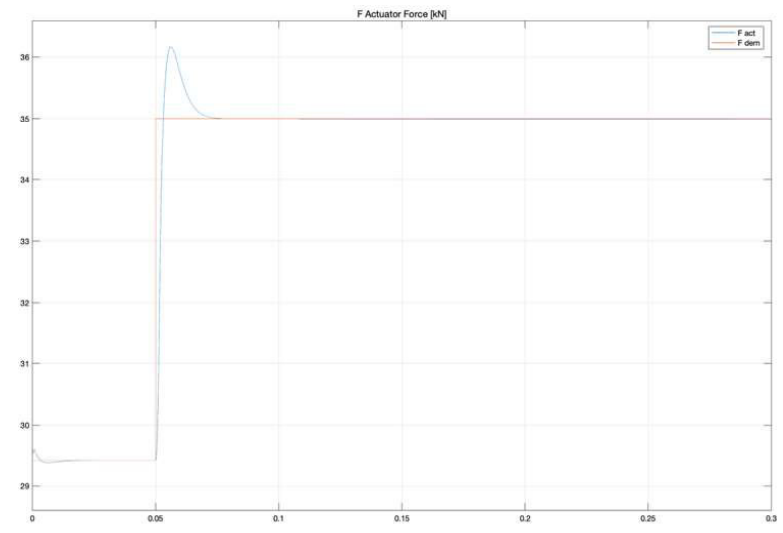

Figure 13: Actuator Force Step Response

The shown force loop tuning is now used to study the characteristics of the suspension system driving across the standardized obstacles. The plots in Figure 14 indicate 3 critical phases passing the obstacle:

1. Transition from the flat into the rising slope The gravity force supports the compensation of the suddenly appearing vertical velocity of the 


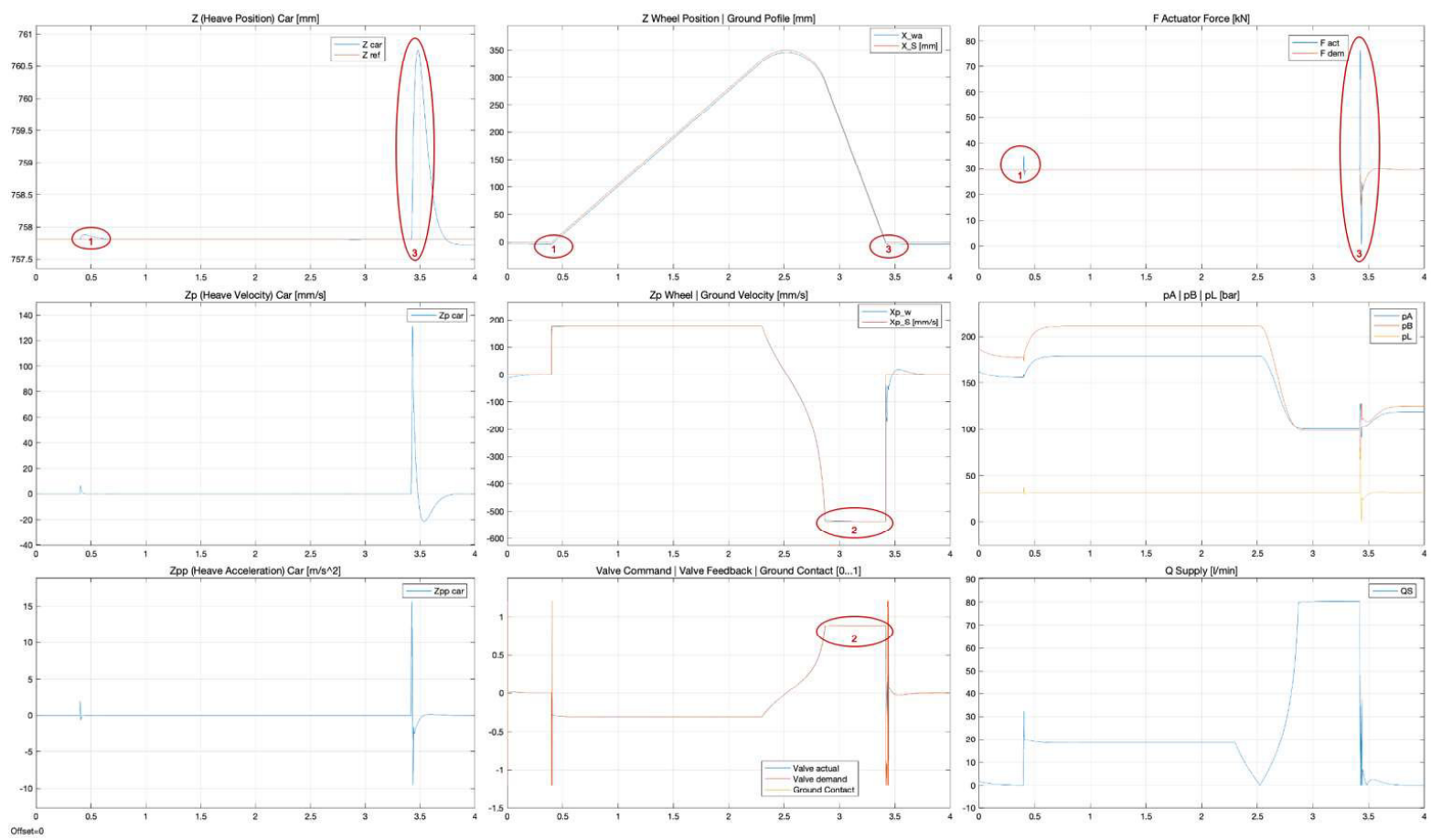

Figure 14: Quarter Car Simulation of one Obstacle, Driving Speed $0.25 \mathrm{~m} / \mathrm{s}$

wheel. The high bandwidth of the force loop in combination with inertia of the whole system effects an acceptable lift in the vehicle entering the rising slope of the obstacle.

2. Falling slope with high vertical velocity This phase of the obstacle is not supported by the gravity force - the actuator has to press the wheel actively down on the ground. The chosen driving speed of $0.25 \mathrm{~m} / \mathrm{s}$ indicates also that the system is close to the static flow limits of the servo valve.

3. Transition from falling into flat slope Entering again the flat slope coming from the falling slope with high velocity represents the most critical phase. During all phases the force controller presses the wheel on the ground with a force, which is equivalent to the gravity force.
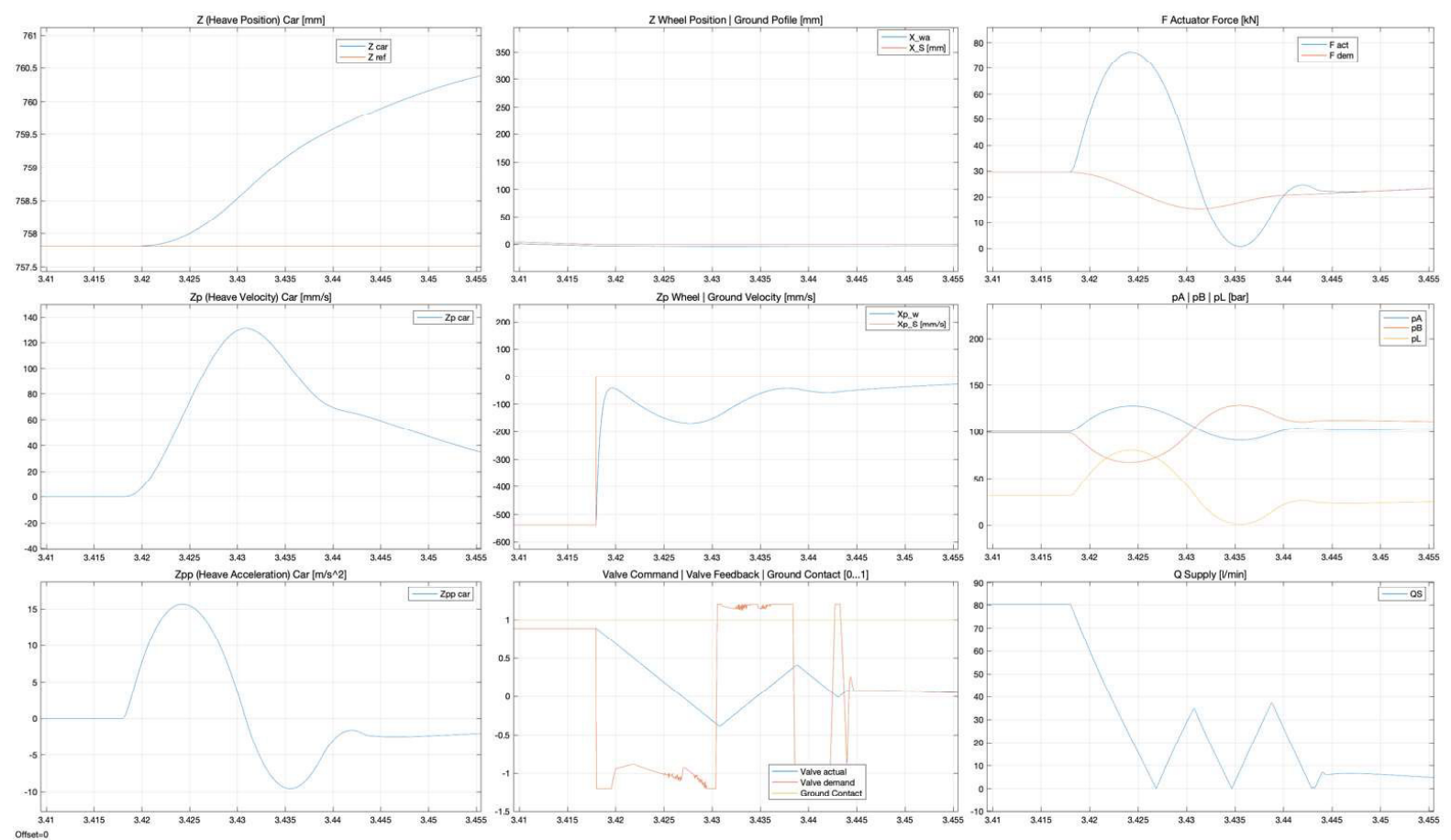

Figure 15: Quarter Car Simulation of one Obstacle, Zoom into Phase 3, Driving Speed $0.25 \mathrm{~m} / \mathrm{s}$ 

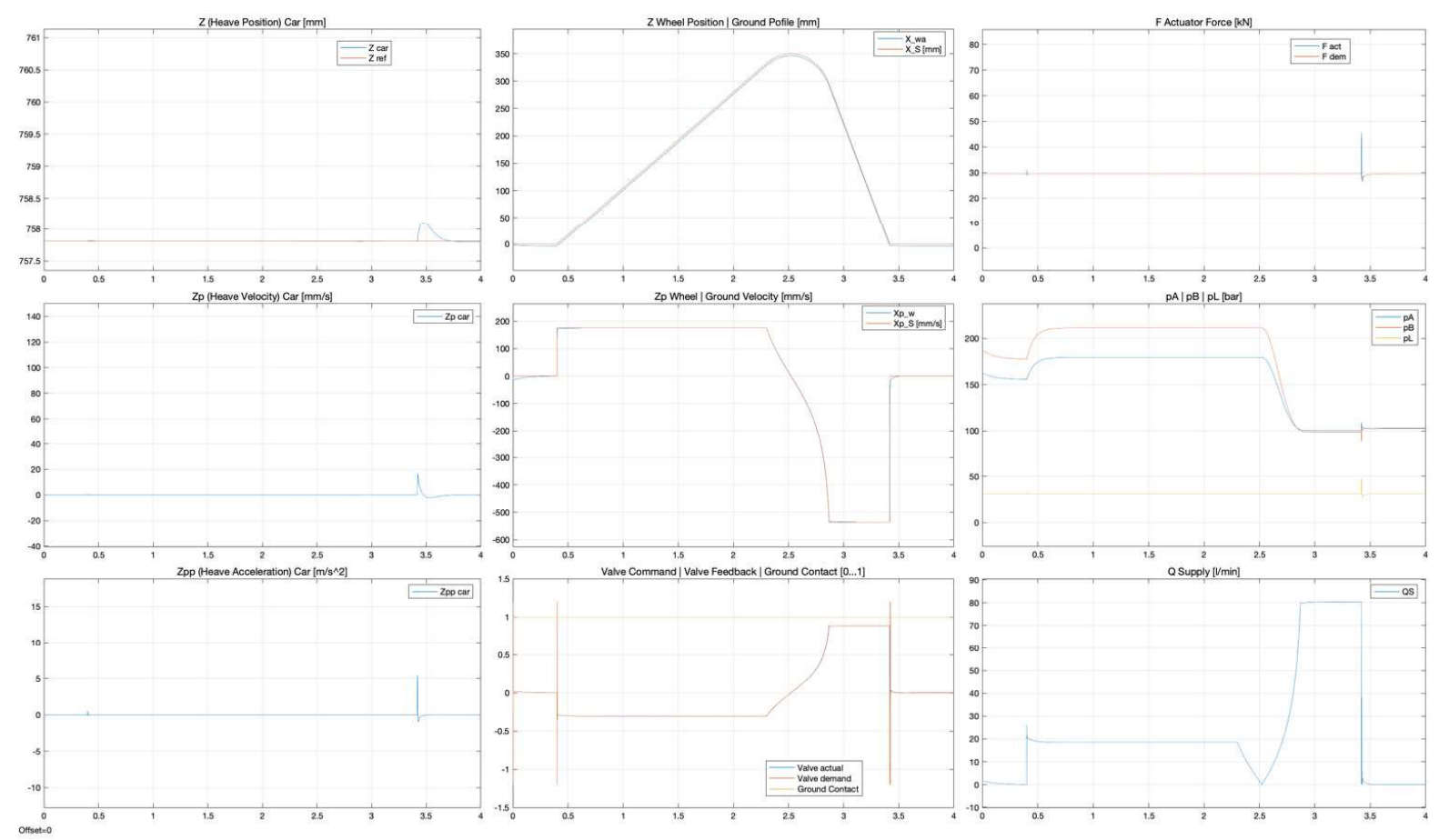

Figure 16: Quarter Car Simulation of one Obstacle, High Response Servo Valve, Driving Speed $0.25 \mathrm{~m} / \mathrm{s}$

This force demand level is adjusted by the heave position controller. The challenge of the transition into the flat domain is the high velocity of the wheel system, actively driven by the hydraulic suspension actuator.

Figure 15 shows a zoom into the critical transition phase. The vertical ground speed changes immediately to zero which effects an increase of the ground contact force. The force controller commands the servo valve to maximum negative opening. The spool of the servo valve follows now the command signal with a limited velocity, which means the spool is still on the positive side, while commanded by negative values.

The used servo valve is characterized by a step response time for a $0 \rightarrow 100 \%$ step of $10 \mathrm{~ms}$. A rework of the valve internal controller structure and the hardware of the valve in form of the linear force motor allows a significant improvement of the dynamic performance of the servo valve. The increase of the bandwidth is one of the well synergy effects, but the focus in this application is on the reduction of the step response time for large magnitudes. The details of this modification of the servo valve are not shown here. All together these changes effect a step response time of $3.5 \mathrm{~ms}$ for a $0 \rightarrow 100 \%$ step and backwards.

Figure 16 shows the impact of the reduced valve response time on the force control loop and therewith on the complete active suspension system. The scaling of Figure 14 and Figure 16 have been chosen equivalent to demonstrate the impact of the dynamic performance of the servo valve.

\subsection{Complete Car Model}

The focus in the quarter car model was on the tuning of the single control loops and the impact of the component characteristics on the system behaviour. The transition from the one dimensional car model to the complete car model allows the investigation of the complete system.

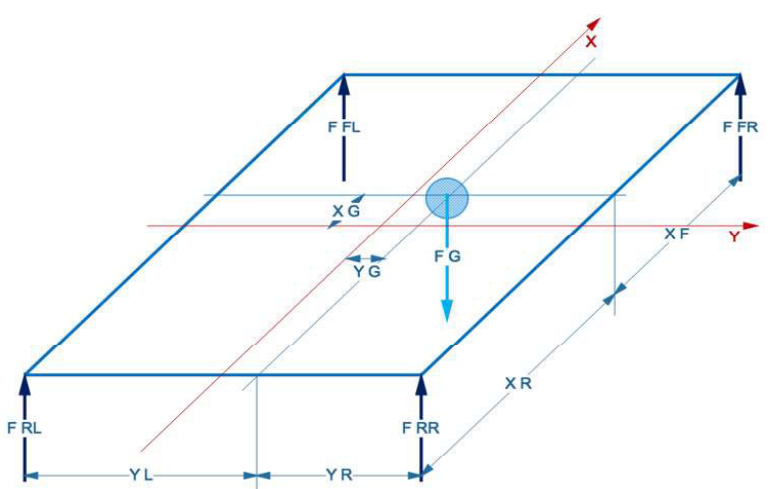

Figure 17: Complete Car Ridged Body Model

The ridged body model for the complete vehicle as shown in Figure 17 calculates the vehicle dynamics as an impact of 5 forces and their actual locations:

- The 4 ground contact forces of the wheels 

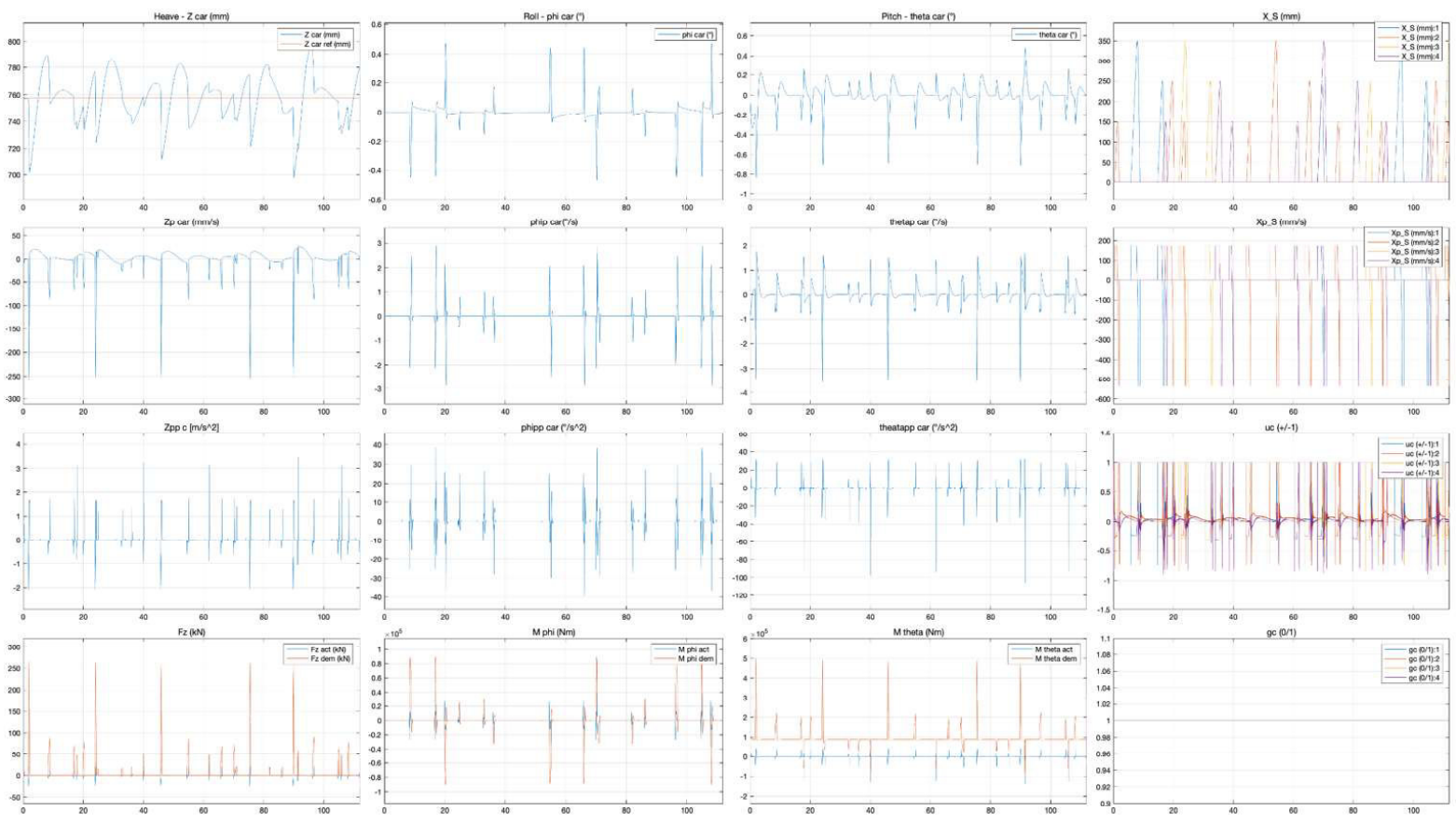

Figure 18: Complete Machine across complete the Test Track, Driving Speed $0.25 \mathrm{~m} / \mathrm{s}$

- The gravity force of the complete system Figure 18 shows the machine driving across the complete test track at a speed of $0.25 \mathrm{~m} / \mathrm{s}$. All control loops on machine stabilization and actuator level are working properly at this driving speed without exceeding the limitations of the loops. The maximum values of heave, pitch and roll movements and accelerations allow comfortable drive of the vehicle across the test track.

Figure 19 shows the same track and driving speed $(0.25 \mathrm{~m} / \mathrm{s})$ on actuator level. The force plots in the second row of the plots indicate the unbalanced position of the centre of gravity biased to the front axle.

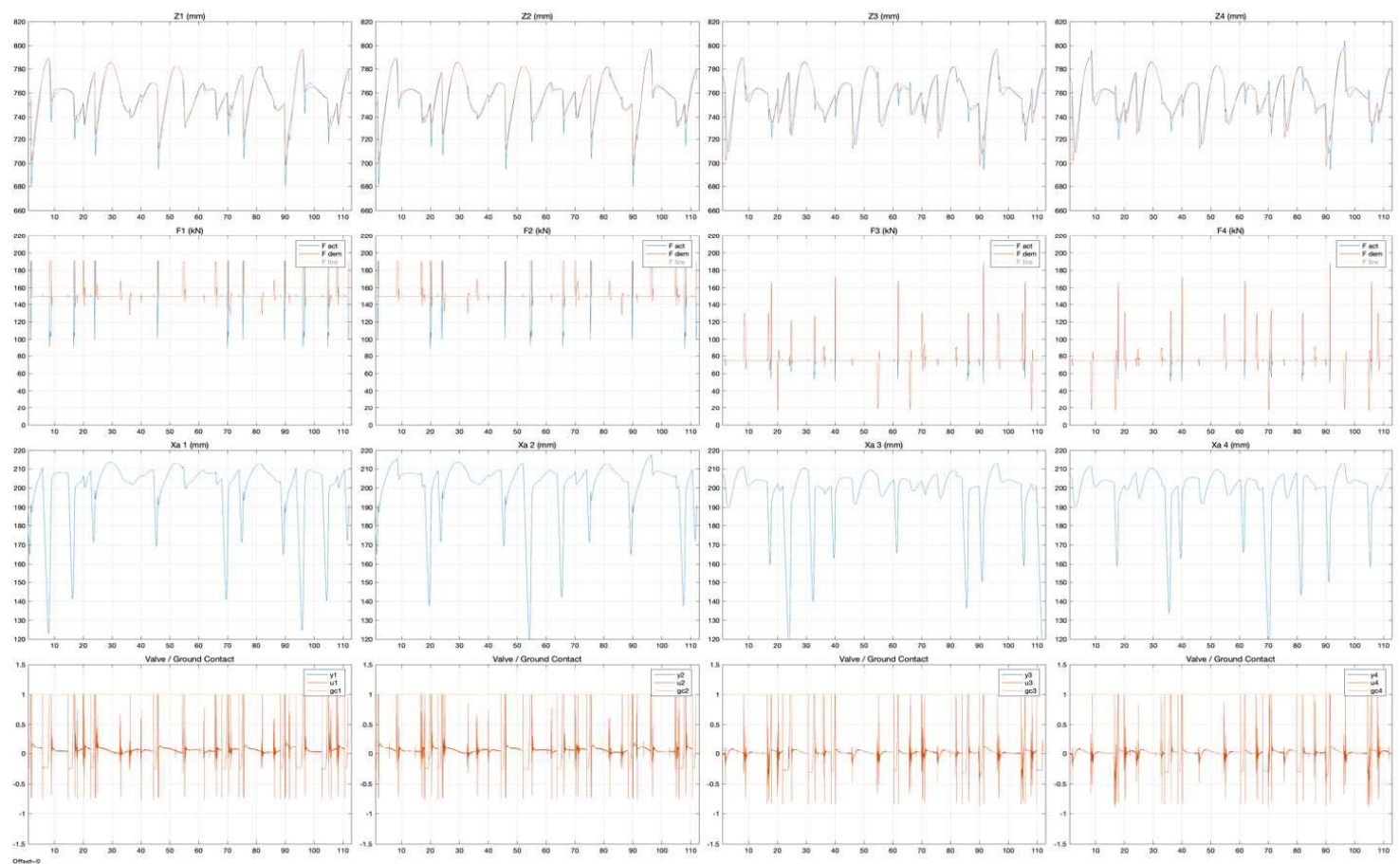

Figure 19: Suspension Actuators versus the complete Test Track, Driving Speed $0.25 \mathrm{~m} / \mathrm{s}$ 

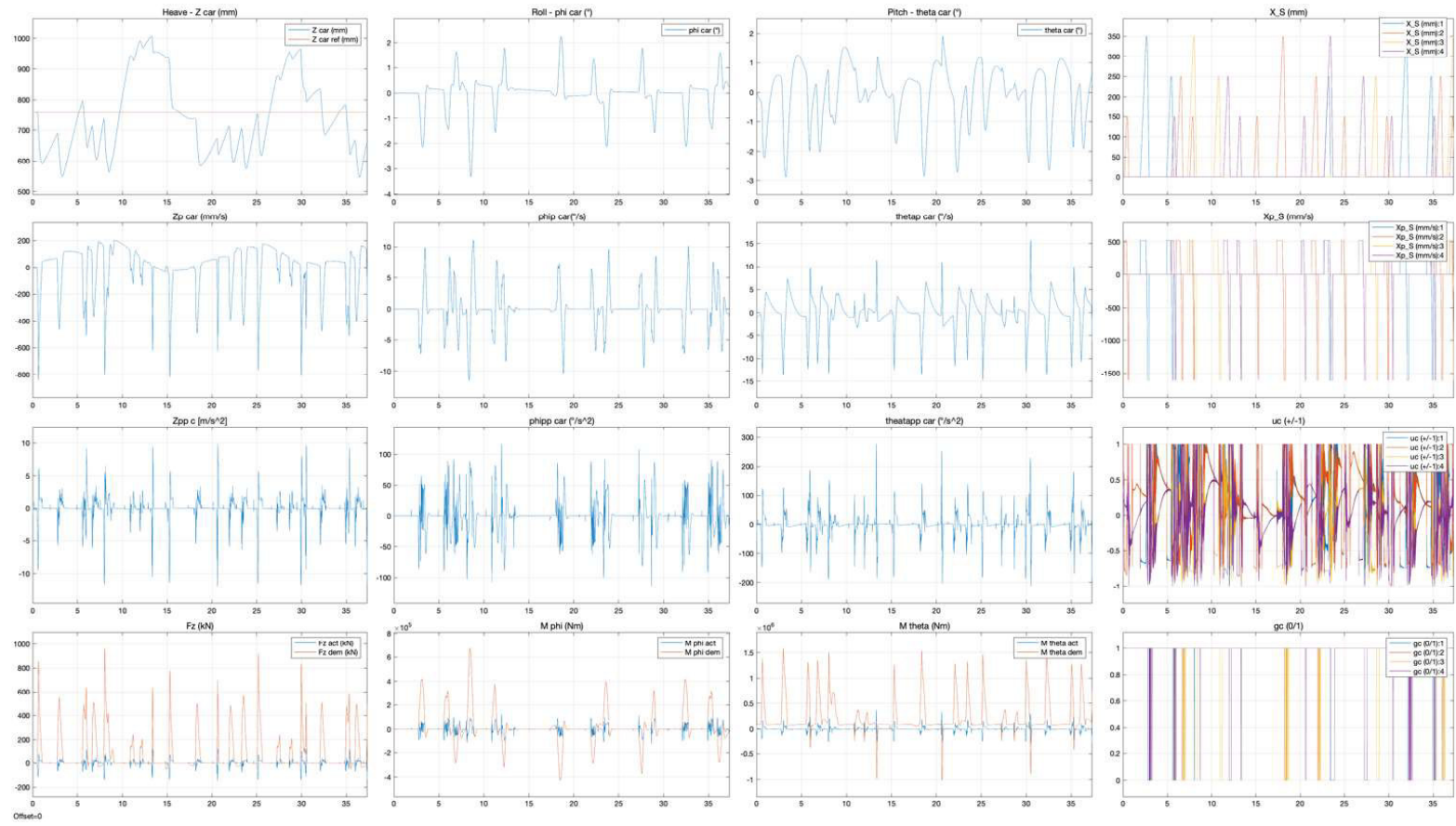

Figure 20: Complete Machine across complete Test Track, Driving Speed $0.75 \mathrm{~m} / \mathrm{s}$

\subsection{Limitations}

An increase of the driving speed up to $0.75 \mathrm{~m} / \mathrm{s}$ as shown in Figure 20 has the effect that the control loops on actuator level are running into limitations, which means the wheels lose ground contact and cannot build up the commanded force to stabilize the vehicle chassis.

The consequence of a further increase of the driving speed would be a bigger sizing of the servo valves and therewith a bigger sizing of the complete hydraulic system. On the other hand, bigger valves would implicit smaller bandwidth and dynamic performance.

\subsection{Real Machine}

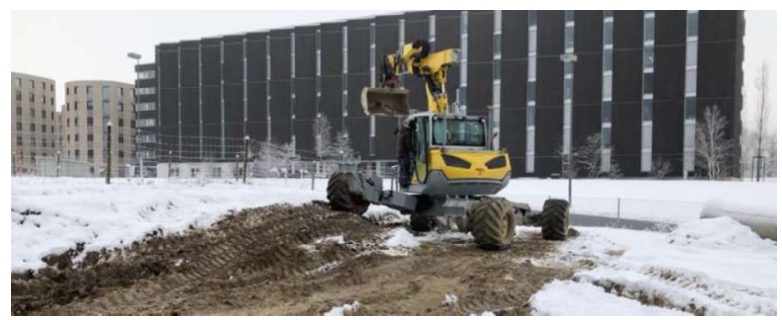

Figure 21: Video Clip (only in presentation)

The behaviour of the real machine with the presented active suspension system will be demonstrated in the conference presentation by a video clip.

\section{CONCLUSION AND OUTLOOK}

The presented active pendulum arm suspension system for mobile machines represents a new performance level of chassis stabilization by use of industrial components.

The critical elements and limitations of these systems have been shown and discussed.

The energy consumption and solutions for the reduction of the energy intake have been developed, but not been presented here due to the limited time for the presentation.

The discussed system represents a high end solution for mobile hydraulic machines like construction or forest machines in the transition from standard machines into automated or at least autonomous machines.

\section{REFERENCES}

[1] Rutting and vibration levels of the On Track concept forwarder on standardized test tracks, Report, $\underline{\text { Skogforsk }}$ 